\title{
The Convergence of Austrian Economics and New Institutional Economics: Methodological Inconsistency and Political Motivations
}

Givalio Palemo

The thesis of the paper is that Austrian economics (AE) and new institutional economics (NIE) are methodologically inconpatible. This casts doubts on the coherence of the programs that are trying to unite these two branches. The structure of my argument follows.

Austrian economics (as typified by Ludwig von Mises and Friedrich A. von Hayek) made precise its peculiarity with respect to neoclassical economics in the 1930s during the planning debate when it strongly attacked the equilibriun method, and it is as an alternative to neoclassical approach that modern AE (typified by Israel M. Kirzner and Ludwig M. Lachmann) actually developed. New institutional economics originated from the inquiry of Ronald $\mathrm{H}$. Coase [1937] on the nature of the firm. The analysis is explicitly developed within a neoclassical context, and its goal, as stated by Oliver E. Williamson $[1975,1985]$, is to explain all economic institutions of capitalism by means of neoclassical tools.

The fact that the theoretical exercises (developed, for instance, by Richard N. Langlois, Andrew Schotter, and Nicolai J. Foss), intended to join the implications of the two approaches, are growing fast thus looks bizarre on methodological grounds: NIE belongs to the methodological approach that is strongly criticized by AE. Notwithstanding this methodological distance, the implications of the two schools are used to support market deregulation, laissez-faire policies, and, in general, the extension of the margins of maneuverability of private capital. My conch-

The author is Assistant of Political Economy at the University of Rome "La Sapienza" (Italy) and at the University of St. Etienne (France). He is grateful to Sandye Gloria-Palemo for her comments and suggestions and to an anonymous referee for editorial assistance. This paper was presented at the annual meting of the Association for Evolutionary Economics, New York City, New York, January 3-5, 1999.

Copyright $\odot$ 1999. All rights reserved. 
sion is that the wo schools have little in common from a methodological viewpoint (and that the projects of their unification fail to take account of their methodological specificity) and that the alliance is founded mainly on a common ideological commitment toward capitalist apologetics and a common political involvement in favor of market sovereignty.

\section{The Convergence of $A E$ and NIE}

There are several theoretical reasons that have led to the consideration of $\mathrm{AE}$ and NIE as complementary. First, one of the main analytical weaknesses of AE is the lack of a theory of the firm, a problem with which NIE begins. ${ }^{1}$ Second, NIE makes sense only in an imperfect information context, ${ }^{2}$ suggesting that the Hayekian theory of knowledge might be relevant also in the explanation of non-market institutions. ${ }^{3}$ A third stimulus has come from the Austrian analysis of the dynamic role of the entrepreneur stressed by Mises and developed by Kirzner for its potential relevance in the new institutionalist explanation of the firm.

But perhaps the most powerful theoretical challenge is to be found in the necessity to reconcile the contradictory results obtained by $\mathrm{AE}$ and NIE since the former argues in favor of the efficiency of the market (with respect to the state) by stressing the benefits of decentralization, and the latter argues in favor of the efficiency of the firm (with respect to the market) by stressing the benefits of centralization. ${ }^{4}$

The result of these stimuli and challenges has now led to a number of general research projects that investigate capitalist institutions within a pluralistic paradigm. ${ }^{5}$ This asks the questions: is this pluralistic approach theoretically coherent? And, more specifically, are $\mathrm{AE}$ and NIE methodologically consistent?

\section{Methodological Inconsistency}

Let us start with a historical characterization of AE. Austrian economics emerged as an independent (heterodox) school in the 1930s. The old idea that AE and neoclassical economics say basically the same things with different languages (the former verbal and imprecise, the latter mathematical and rigorous) is explicitly rejected by Austrians, and during the planning debate ${ }^{6}$ (in which the planning supporters argued from a neociassical perspective ${ }^{7}$ ), the leaders of the Austrian school progressively clarified their differences with respect to neoclassicals. ${ }^{8}$

Mises's contribution to the characterization of AE can be found in his criticism of neoclassical homo economicus as a reactor and in his proposal of homo agens as an actor making decisions in a historical time context; the introduction of historical time puts uncertainty in the forefront, giving human action a necessarily speculative dimension. In a world of active economic agents, the concept of competition ac- 
quires a new meaning: competition is a catallactic process oriented toward the greatest satisfaction of the sovereign consumer.

The Misesian concent of competition is developed by Hayek [1937, 1945, 1949, 1978] in his theory of decentralized knowledge as the foundation for the efficiency of a market system. ${ }^{10}$ According to Hayek, competition is not a state of affairs, but a process whose desirability stems from its ability to discover and efficiently allocate the relevant information. Hayek's analysis of competition is based on the assumption that equilibrium is a theoretical state that is never reached and, more importantly, is a useless concept since it is conceptually impossible to know all data definirg it [Hayek 1937]. Hayek thus explicitly attacks the equilibrium method, and it is on this methodological position that modem $A E$ analyzes capitalist institutions. 11

The characterization of NIE is easier, and it can simply be defined is an attempt to analyze economic institutions by means of neoclassical methodological tools. Although to some extent NIE was bon from criticisms of the neoclassical paradigm for its inability to explain capitalist institutions, it has in fact developed according to the very same logic. Given that in a perfect theoretical context, such as that defined by the general equilibrium framework, there is no economic explanation of capitalist institutions (since all centralized and decentralized allocation mechanisms are compatible with Pareto efficiency), NIE introduces a number of imperfections into that theoretical context (questioning the assumptions of perfect information, certainty, and full rationality) that eliminate the equivalency results characterizing the general equilibrim context. By using the efficiency principle as the engine of evolution, it provides an explanation for the coexistence of different allocation mechanisms (planning, firms, and markets) as solutions to specific silocational problems in which each mechanism is the most efficient.

Not only the method, but also the definition of the problem and the analytical objectives are those of neoclassical economics: the problem of economics is the allocation of scarce resources. Capitalist institutions are identified with allocational mechanisms, and the problem of their nature is defined as a comparison between allocation mechanisms. Methodologically NIE does not break in any sense with neoclassical orthodoxy, but is an enlargement of pure neoclassical economics.

Three dimensions of theoretical context deserve attention: information, time, and uncertainty. In the pure neoclassical context, these three dimensions are extremely simplified: information is perfect (there are no problems in acquiring it and/or in processing it, and there are no asymmetries in its distribution among individuals); and time and uncertainty are simply assumed away by the definition of a static and certain context. Starting from such a theoretical context, it is possible to introduce imperfections along the three dimensions; however, the very fact of assuming the perfect neoclassical context as the starting point restricts the range of possibilities along which imperfections can be introduced. 
The perfect neoclassical context is characterized by two general features: (1) agents decide by solving constrained optimization problems, and (2) social interactions take place in equilibrium. Any attempt to extend or generalize such a context by introducing imperfections along one or more of the three dimensions must be compatible with these two features; otherwise, internal consistency problems emerge.

New institutional economics attempts to extend the applicability of the neoclassical framework by relaxing assumptions of perfect information, statics, and certainty. The way this can be done, if the two general features of the neoclassical context must be preserved, is by formalizing information, time, and uncertainty as new variables and/or new constraints to the decision-making problems of agents. This method of extending the neoclassical context restricts the meanings that the three dimensions can assume: each dimension must be adapted to the neoclassical context. The concepts of information, time, and uncertainty, once adapted, assume a particular meaning-the one compatible with the assumptions of optimization and equilibrium. ${ }^{12}$ It is for this reason that NIE ends up with its particular definitions of information, time, and uncertainty: information is imperfect but defined as a closed set. Imperfect information implies positive transaction costs; the assumption of a closed information set ensures, however, that such costs are perfectly specifiable ex ante. As far as time is concerned, although the concepts of specificity and sunk costs suggest that NIE gives importance to historical processes and cumulative mechanisms, it remains in fact faithful to a logical conception, rather than to a historical one: this stems directly from the analytical method of equilibrium comparative statics. Uncertainty, coherently with this picture, is conceptualized as quantitatively measurable, and the set of the states of nature is assumed to be exhaustively known by decision makers. ${ }^{13}$ Remove one of these assumptions of the three dimensions and the whole project of NIE becomes vague, since transaction costs can no longer be specified. ${ }^{14}$

Austrian economies, on the contrary, defines its theoretical context ex nihilo, with no attempt to preserve methodological compatibility with neoclassical economics. Knowledge problems are discussed in a dynamic and uncertain context in which the internal dynamism of human action makes the assumption of equilibrium contradictory. The problem is that $\mathrm{AE}$ insists on information and time and only occasionally discusses uncertainty. But the point is that once information and time are conceptualized in the Austrian sense, the attempt to preserve a general compatibility with the neoclassical context by means of a conceptualization of uncertainty as risk would create intemal consistency problems. ${ }^{15}$ Anyway, independent from the problem of the correct interpretation of Mises's and Hayek's positions on uncertainty, $\mathrm{AE}$ explicitly attempts to define an approach based precisely on the refusal of individual optimization and equilibrium, and the introduction of historical time and 
knowledge problems is sufficient to this aim. My conclusion is that Austrian and neoclassical-new institutionalist theoretical contexts are incompatible. ${ }^{16}$

But then, to what extent will a synthesis still be relevant? My answer is that any attempt to synthesize these two schools that does not take into account the incompatibility between theoretical contexts will necessarily be grounded on a complementarity more apparent than real.

The first problem is with terminology. Without entering into the details of the different $\mathrm{AE}$ and NIE synthesis projects, 1 notice a general confusion in the use of the terms on which both AE and NE define their frameworks. The terms coordination and competition are perhaps the mose significant. Their meanings are strictly linked to the features of the theoretical context.

In the Austrian context, the principle of competition is an ex post mechanism that rules social interaction without anyone intentionslly attempting to eliminate existing incompatibilities; its (supposed) efficiency stems precisely from the disequilibrium signals (synthesized in the price system) produced by the manifestation of plan incompatibilities. The principle of coordination, on the contrary, works necessarily $e x$ ante by acting on the processes of formulation of individual plans as an attempt to deliberately eliminate incompatibilities before social interaction takes place. The skepticism of Austrians about this mechanism stems from their theoretical context, a context in which there is no reason why coordination activity should be effective. Both competition and coordination are thus considered as imperfect principles unable to completely eliminate the existing plan incompatibilities, but this does not prevent Austrians from comparing them on the basis of their relative effectiveness in reducing in time such incompatibilities.

In NIE the use of the equilibrium method leads instead to defining the principle of cocrdination as a perfect mechanism that is able to guarantee the full compatibility of plans. Coordination takes place in virtual time, since interaction does not $o c-$ cur before full plan compatibility (equilibrium) is reached. Competition in this context cannot be considered for its ex post disequilibrium signals (as in the Austrian sense), but simply as an $e x$ ante force acting on plan formulation. As we can see, this diversity of terms is simply a manifestation of the difierent visions of economic problems on which the different theoretical contexts are based.

A second problem is analytical. The definition of a disequilibrium context by $\mathrm{AE}$ leads to the adoption of an ex ante perspective both in the analysis of the behaviors of the agents of the model and in the normative prescriptions of the analyst. Only process matters, not its (eventual) final state of convergence. The Awstrian agent takes for granted that he cannot know what others will do and this looks at the future process of social interaction from an ex ante perspective. Similarly, the Aistrian analyst knows that equilibrium is analytically irrelevant and formulates his nomative prescriptions by looking at the dynamic properties of the process of social 
interaction. It is precisely on this $e x$ ante perspective that $\mathrm{AE}$ claims that the market is efficient.

On the contrary, NIE, being based on equilibrium method, adopts an ex post perspective. The new institutionalist agent acts by considering all the possible actions of other agents and figures out the best response to them; he thus positions himself in an ex post situation and from there decides the best thing to do. The same holds for the new institutionalist analyst, who assumes that a situation in which nobody has an interest to move away from has already been reached and compares it with all the ofher possible equilibrium situations. The assumption of equilibrium does not allow an appraisal of the process through which equilibrium is (eventually) reached. Equilibrium analysis implies that the process of convergence toward equilibrium is already completed, and the appraisal of the equilibrium positions refers thus to an ex post perspective.

But then (1) NIE analyzes the state of affairs in which the Austrian coordination problem does not exist, and (2) AE discusses a problem that is not analyzable within $\mathrm{NIE}$ framework. My conclusion is that $\mathrm{AE}$ and $\mathrm{NEE}$ discuss different problems, which they call by the same names. This not only leads to wrong conclusions if one tries to derive complex propositions from the propositions proved on each single contex (since theorems holding in a given theoretical context are not necessarily valid in a different context), but it also impedes any easy translation of propositions derived in one context into the language of the other. ${ }^{17}$

\section{Political Motivations}

Notwithstanding this methodological incompatibility, the implications of both $A E$ and NIE are used to support neoliberal policies aimed at widening the sphere of private property and the social field in which market laws reign. Common political action can be observed at two different levels-theoretical and applied.

At the theoretical level, a common objective is purely apologetic and claims the efficiency/desirability of capitalism. Such a claim is not new; its main theoretical reference is the two welfare theorems in the general equilibrium model. But such a model is unrealistic, and if one tries to apply it to real capitalist systems, one finds that a lot of intervention is needed. ${ }^{18}$ So the defense of (real) capitalism cannot be based on the general equilibrium framework. ${ }^{19}$ But it is here that AE and NIE provide useful contributions: they argue the efficiency of capitalism as it really is, with all its capital concentrations, monopolies, and cartels. ${ }^{20}$ The problem then is not to try to adjust reality to the perfectly competitive model according to which a monopoly is Pareto inefficient and undesirable, but to explain why monopolies are efficient and socially desirable (as long as they are private).

This brings us to the applied level: once the efficiency of capitalism has been "proven," a framework for economic policies (and, in particular, for antitrust analy-

Copyright $\odot$ 1999. All rights reserved. 
ses) is needed. It is here that the distance from the general equilibrium framework is particularly attractive: the attempt to deny the existence of monopolies and deviations from the model of perfect competition raises skepticism; it is more effective to concede that they exist . . but only because they are efficient?

By arguing on different (and incompatible) theoretical contexts, $A E$ and NIE manage to affirm the principle of the maximum autonomy for private capital and for implementation of policies of privatization and deregulation, even in those cases in which the standard neoclassical competitive model (the only other theoretical approach they take into consideration) would prescribe the opposite. Here is ultimately what the two approaches have in common.

\section{Notes}

1. A number of contributions have been developed in such a direction. See Schoter [1981], Langlois [1986a, 1992], and Langlois and Robertson [1995].

2. In perfect information context, all institutional arrangements are equivalent from the viewpoint of their Pareto efficiency. This implies that the NIE method of explaining the instiutions of capitalism as Paretorefficient solutions of allocational protelems can be defined only in an imperect information context.

3. More precisely, there have theen a number of attempts to use the Hayekian theory of knowledge as a discovery procedure in the market as the basis for a theory of the firm. See Foss [1994, 1997! and loannides [1997].

4. The solution to such a contradiction is found by assuming (1) the existence of an optimal degree of centralization for each allocation problem and (2) the emergence of a specifie in stitution every time an allocation problem is not solved efficiently by the existing institutions. These two assumptions allow explanations of the coexistence of different institutions in capitalism as efficient solutions to specific allocational problems. Both the Austrian and the new institutionalist theory of efficiency of capitalist institutions have been abundantly criticized for their internal inconsistency and historical falseness. See Dugger 11989 , 1992], Fourie [1989, 1991], Hodgson [1988], Marglin [1991], and Pitclis [1991, 1993].

5. In Langlois's [1986b, 1-2] approach, the border of NIE is so broadly defined that it includes the evolutionary theory of Richard $R$. Nelson and Sidney Wuter, the moderm Austrian school of Kirzner, the transaction cost economics of Willamson, and certain aspects of the property rights literature.

6. The challenge to socialist econonics was launched by the neoclassical economists Vilfredo Fareto and Enrico Barone at the beginning of the century, but it was only with the iniervention of Mises in 1920 that is became a certral theme in academic debates.

7. The most important figures on the pro-planning side who participated in the debate are Oskar R. Lange, Abba P. Lener, and Fred M. Taylor. Marxian economists either remained distant from market socialism, arguing that it was incompatible with Marxist thought [Dobb 1937; Kornas 1993], or simply did not participate in the debate (as in the case of the Soviet school), considering it a bourgeois, intellectual speculation that was basically useless from the viewpoint of the problematic aspects posed by the practice of socialist pianning [Nove and Nuti 1972].

8. They have basically rediscovered, in the interpretations of Vaughn [1994] and GloriaPalermo [1999], the originality of Carl Menger, the founder of the Austrian school, whose nethodological traits were already distinct from those of the founders of the reoclassical 
school, Stankey W. Jevons and Lśon Walras, since the time of the so-called marginalist revolution in the $1870 \mathrm{~s}$.

9. The fundamental contributions of Mises to the planning debate are his 1920 article (which opens theoretical hostilities of Austrians against socialism) and his 1936 book. The most clear and explicit statement of the fearures of $\mathrm{AE}$ in the interpretation of Mises is his 1949 book, Human Action, which appeared after the official closure of the planning debate. It incorporates the refiections that led to the characterization of the Austrian paradigm as independent and alternative to the neoclassical one.

10. His most polemical works against socialist planning are published in his 1935 book.

11. This methodological position is also the only one that gives some validity to the Misesian and Hayekian criticisms of planning according to which in centralized systems agents have no incentive to act for the social good and to discover and efficiently use the dispersed knowledge. The possibility of deriving from these arguments the Austrian theses against socialist planning and in favor of laissez-faire capitalism is, however, still an open question. In this connection, note that within modern AE the debate on planning is still considered an actual issue [Lsvoie 1985; Kirzner 1987]. My position on the matter is that AE is incapable of coherently arguing for the superiority of capitslism over socialism even within a context of historical time, radical uncertainty, and imperfect information as the one defined by Mises and Hayek [Palermo 1998].

12. Within neoclassical economics, this is easily visible in the introduction of time and uncertainty into the general equilibrium framework: the indexation of goods according to time and states of nature is not simply an extension of the static and certainty model, it is also the only way to incorporate time and uncertainty into the model.

13. Decision-making processes are thus defined as optimization problems under risk cond:tions. For a discussion of the different conceptuabizations of uncertainty and a taxonomy of different economic sehools with respect to it, see Lawson [1988].

14. A problem, by the way, that does not worry new institutional economists since none of them has felt the need to provide a rigorous and operative definition of transaction costs [Hodgson 1988; Pitelis 1991].

15. The ambiguity of $\mathrm{AE}$ in the definition of uncerainty is at the basis of conflicting positions among modern Austrian economists and of different interpretations of the relation between $\mathrm{AE}$ and neoclassical economics. Two relevant positions within modern $\mathrm{AE}$ are those of Kirzner and Lachmann, who emphasize, respectively, the complementarity and the antagonism between AE and neoclassical economics.

16. Elsewhere have criticized the theoretical context of $\mathrm{AE}$ by arguing that Austrians do not discuss uncertainty sufficiently and open themselves to criticism concerning the internal consistency of their theoretical framework. If, as some suggest, uncertainty can be formalized as risk, then interpretative problems emerge insofar as the contribution of Mises and Hayek to the discussion of knowledge and time are concerned. In this case, the compatibility of AE and NIE might, to some exten, be defended, but then the attempt to synthesize them would become pointless, since the original contributions of $\mathrm{AE}$ would be strongly cut down to size. If, on the contrary, uncertainty is conceptualized as radical (an interpretation that I tend to share), then the Austrian theoretical context is incompatible with the neoclassical-new institutionalist one.

17. The argument developed here is not that a synthesis of $\mathrm{AE}$ and NIE is impossible, but rather that it should pass through a discussion of their theoretical context (a discussion that 1 have not seen in the works here considered). In my view, once defined a coherent theoretical context, it is useful to analyze the robustness of the theses derived in different contexts and to take inspirations from different schools of thought.

18. I am still looking for a single sector characterized by the absence of increasing returns, externalities, and public goods (three of the necessary conditions for the Parcto efficiency of competitive equilibria). 
19. Also because, as alreacy noted, in such a theoretical contex even socialist planning is Pareto efficient. The fact then that Pareto efficiency does not imply social desirableness is a question that I cannot discuss here. See, for instance, Hausmar and McPherson [1996].

20. There are numerous criticisms of the validity of the arguments of $A E$ and NIE concening the efficiency/desirability of capitalism. The atternpt to discuss them here would bring me too far with respect to the purpose of this paper, which is simply about the nutual (inj)consistency of the two approaches.

\section{References}

Clark, C. M. A. "Spontaneous Onder Versus Instituted Brocess: The Market as Cause and Effect." Journal of Economic Issues 27, to. 2 (Iune 1993): 373-83.

Coase, R. H. "The Nature of the Firm." Economica 4 (1937): 386-405.

Dobb, M. Political Economy and Capitalism: Essays in Economic Tradition. London: Routiedge, 1937.

Dugger, W. M., ed. Radical Institutionalism: Contemporary Voices. New York: Greenwood Press, 1989.

- An Evolutionary Theory of the State and the Market." In The Stratified Srate: Radical Institutionalist Theories of Participation and Duality, edited by W. M. Dugger and W. T. Waller. London: M.E. Shanpe, 1992.

Foss, N. J. "The Theory of the Firm: The Austrians as Precursors and Critics of Contemporary Theory. "Review of Ausirian Economics 7, no. 1 (1994): 31-65.

. "Austrian Insights and the Theory of the Firm." Advances in Rustrian Economics no. 4 $(1997): 175-98$.

Fontie, F. C. v. N. "The Nature of Firms and Markets: Do Transaction Cost Theories Help?" The South African Joumal of Economics 57 , no. 2 (1989).

. "The Nature of the Market: A Structural Analysis." In Rethinking Economics: Markets, Technotogy and Economic Ebolution, edited by G. M. Hodgson and E. Screpanti. Aldershot: Edward Elgar, 199 .

Gloria-Palermo, S. The Evolution of the Austrian Tradition: From Menger so Lachmann. London: Routledge, 1999.

Hausman, D., and M. McPherson. Economic Analysis and Moral Philosophy. Cambridge: Cambridge University Press, 1996.

Hayek, F. A. von. Collectivist Economic Plaming: Crisical Studies on the Possibilities of Socialism. London: Routledge and Kegan Paul, 1935.

. "Economics and Knowledge." Economica 4 (1937): $33-54$.

"The Use of Knowledge in Society." American Economic Review 35, no. 4 (September (945): $519-30$.

. "The Meaning of Competition." In Individualism and Economic Order, edited by F. A. von Hayek. London: Roulledge and Kegan Pari, 1949.

. New Studies in Phibosophy, Folitics, Economics and the History of Ideas. London: Routledge and Kegan Paul, 1978.

Hodgson, G. M. Econonics and Institutions: A Manifesto for a Modern Institutional Economics. Cambridge: Polity Press, $\$ 988$.

Ioannides, S. "Towards an Austrian Perspective on the Firm." Sth EAEPE Conference, Athens, Greece, November 1997.

Kirzner, I. M. Competition and Entreprenewrship. Chicage: University of Chicago Press, 1973.

"The Econormic Calculation Debate: Lestons for Austrians." Review of Arstrian Economics 2 (1987): $1-18$.

Komai, J. "Market Socialism Revisited." In Market Socialsm. The Current Debate, edited by P. Bardhan and 1. E. Roeme: Oxford: Oxford University Press, 1993. 
Lachmann, L. M. The Market as an Economic Process. Oxford: Blackwell, 1986.

Langlois, R. N., ed. Economics as a Process: Essays in the New Institutional Economics. Cambridge: Cambridge University Press, 1986a.

. "The New Inetitutional Economics: An Introductory Essay." In Econonics as a Process: Essays in the New Institational Economies, edited by R. N. Langlois. Cambridge: Cambridge University Press, 19866 .

. "Orders and Organizations: Towards an Austrian Theory of Social Institutions." In Austrian Economics: Tensions and New Directions, edited by B. J. Caldwell and S. Boehm. Boston: Kluwer, 1992.

Langlois, R. N., and P. L. Robertson. Fims, Markets and Economic Change. London: Routledge, 1995.

Lavoie, D. Rivalry and Central Planning. Cambridge: Cambridge University Press, 1985.

Lawson, T. "Probabiliy and Uncertainty in Economic Analysis." Journal of Post Keynesian Economics no. 11 (Fall j988): 38-65.

Marglin, S. A. "Understanding Capitalism: Control versus Efficiency." In Power and Economic Institutions, edited by B. Gustavsson. Aldershot: Edward Elgar, 1991 .

Mises, L. von. "Economic Calculation in the Socialist Commonwealth." In Collectivist Economic Planning: Critical Studies on the Possibilities of Socialism, edited by F. A. von Hayek. 1920. Reprint. London: Routledge and Kegan Paul, 1935. Socialism. Indianapolis: Liberty Press, 1936. 1949.

Human Action: A Treatise on Economics. London: William Hodge and Company Limited,

Nove, A., and D. M. Nuti, eds. Socialist Economics. Hamondsworth: Penguin Booxs, 1972.

Palermo, G. "The Socialist Planning Debate: A Historical and Analytical Reconsideration." Discussion Paper of the University of Rome "La Sapienza" New Series, no. 31, 1998. Forthcoming in History of Economic Ideas.

Pitelis, C. Market and Non-Market Hierarchies: Theories of Institutional Failure. Oxford: Basil Blackwell, 1991.

, ed. Transaction Costs, Markets and Hierarchies. Oxford: Blackwell, 1993.

Schotter, A. The Economic Theory of Social Instibutions. Cambridge: Cambridge University Press, 1981.

Vaughn, $\mathrm{K}$. Austrian Economics in America: The Migration of a Tradition. Cambridge: Cambridge University Press, 1994.

WhHiamson, O. E. Markets and Hierarchies: Analysis and Anti-trust Implications. A Study in the Economics of Intemal Organization. New York: The Free Press, 1975.

. The Economic institutions of Capitalism: Firms, Markets, Relational Contracting. London: Macmillan, 1985. 